\title{
EL PAPEL DE BRASIL EN LA HISTORIA DE ESPAÑA Y PORTUGAL
}

Autor de importantes escritos e investigador activo en los ámbitos de Historia Moderna de Portugal y España, Pedro Cardim es reconocido a nivel internacional como uno de los más prolíficos historiadores del momento. Desde su puesto de profesor titular en la Faculdade de Ciências Sociais e Humanas de la Universidade Nova de Lisboa, y como vicedirector del Centro de História de Além-Mar, Pedro Cardim ha venido desarrollando importantes trabajos dedicados al entendimiento de la realidad portuguesa en el contexto propio de la Edad Moderna. Sus estancias en la École des Hautes en Sciences Sociales de París, en la Universidad de Viena, en universidades españolas como la Autónoma de Madrid, la Pablo de Olavide de Sevilla o la Universidad de Granada y, finalmente, en la Universidad de Nueva York han contribuido favorablemente a enriquecer sus perspectivas. En sus investigaciones más recientes, el historiador hace una apuesta clara por enfoques globales, comparativos y de análisis conectado, en las que siempre ha aludido a la necesidad de acercarse no solo al contexto ibérico, sino también a los espacios extra europeos, para entender el devenir histórico de Portugal desde la Edad Moderna hasta nuestros días.

A lo largo de su carrera profesional los intereses de Pedro Cardim han oscilado desde la configuración cultural y política de Portugal y de España en los siglos XVI y XVII hasta la construcción, por parte de ambos países, de sendos imperios coloniales en América a lo largo del mismo periodo. Su especial atención a las similitudes y diferencias entre ambas identidades, presentes tanto en contextos europeos como americanos, han iniciado una tercera vía: la de las interacciones que, a nivel político, social y cultural, se constataron a ambos lados de las fronteras de estos países, ya fuera en la peninsular o en la americana.

Como no podía ser de otra manera, sus intereses iniciales por la configuración de Portugal durante la Modernidad le llevaron, de una manera casi natural e inintencionada, a estudiar profundamente el periodo de la Unión de Coronas (1581-1640). Con este concepto se hace referencia a las casi seis décadas que Portugal formó parte de la Monarquía Hispánica, momento que dio inicio cuando Felipe II de España fue aclamado rey de Portugal (1581) y que finalizó al proclamar João IV el fin del régimen Habsburgo en los territorios portugueses (1641). Dada la magnitud geográfica de la Monarquía Hispánica y la complejidad administrativa de cada uno de los espacios que la componían, Pedro Cardim centró originalmente sus estudios en el caso portugués peninsular. Comenzó entonces una importante labor de investigación que analizaba la manera a través de la cual Portugal se había integrado en la Monarquía Hispánica. Sus trabajos Portugal unido y separado (2014), así como numerosos artículos que aparecen ahora reagrupados en Portugal y la Monarquía Hispánica (ca. 1550 - ca. 1715) (2017) son los más representativos de esta etapa de investigación.

No obstante, Brasil, al igual que el resto de los territorios ultramarinos portugueses, también formó parte y hubo de integrarse en la Monarquía Hispánica. Conocedor ya de las similitudes, diferencias e interacciones existentes entre los territorios de España y Portugal en América durante el periodo moderno, Pedro Cardim centró su interés de manera específica en Brasil y, más concretamente, en cómo había sido integrado este vasto territorio al gobierno de los Habsburgo. En su publicación 'O governo e a administração do Brasil sob os Habsburgo e os primeiros Bragança' (2004) planteó importantes perspectivas que no hicieron más que enriquecer las interpretaciones existentes hasta el momento sobre Brasil. Asimismo, la participación casi simultánea de Pedro Cardim en proyectos como 'Red Columnaria', cuyo resultado fue Polycentric Monarchies (2012), o el proyecto Baía 16-19 (20122016), que culminó con la publicación de Salvador da Bahía: Retratos de uma cidade atlântica (2016), han contribuido favorablemente a la definición de sus dos líneas de investigación americanistas. La primera de ellas se centra en el estatus político de los territorios luso-americanos durante la Edad 
Moderna, destacando 'A incorporação de territórios e o estatuto político do espaço ultramarino' (2015) o 'Political Status and Identity: debating the Status of American Territories across the 16th and 17th century Iberian World' (2016). La segunda, por su parte, pone el énfasis en las interacciones existentes entre los actores peninsulares y los de ultramar, tanto a través de la comunicación escrita o la presencia en los organismos peninsulares de gobierno imperial. En artículos como 'Les représentants de municipalités extra-européennes dans les Cortes de Portugal' (2013), o 'A comunicação entre a Câmara de Salvador e os seus procuradores em Lisboa durante a segunda metade do século XVII' (2016) se destaca el poder creciente de los poderes locales, otrora definidos como periféricos, pero cada vez más protagonistas de las Monarquías de la época moderna.

Con esta impresionante y variada trayectoria, Pedro Cardim demuestra ser un historiador versátil, con inquietudes múltiples y experto en metodologías diversas. Estas dos grandes áreas de estudio, la ibérica y la americanista, otrora distantes y alejadas tanto en términos educativos como de investigación, confluyen y avanzan parejas en la obra historiográfica de Pedro Cardim, en la que Brasil tiene cada vez un papel más destacado. El historiador aparece en esta entrevista no solo como un investigador consagrado, sino como un ejemplo de continua formación académica y adaptación a los nuevos tiempos, ya sean éstos sociales, políticos o historiográficos.

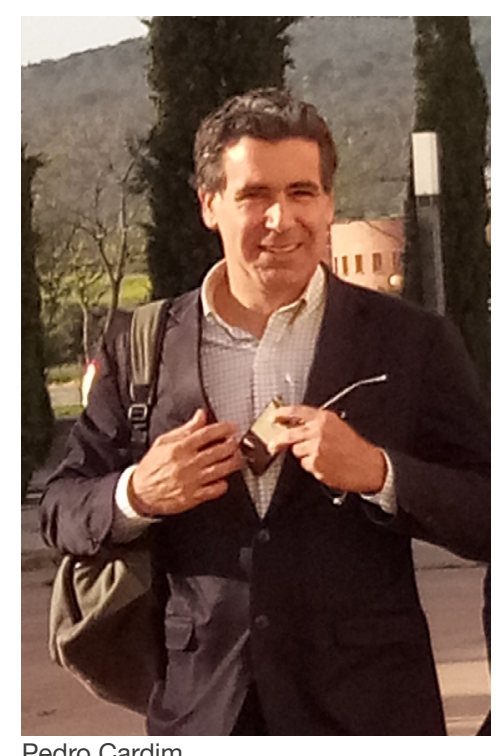

Imagen cedida por Pedro Cardim. Archivo personal.

\section{Irene María Vicente Martín}

Doctoranda en el Instituto Universitario Europeo (Italia).

Irene.Vicente@EUl.eu 


\section{DEDICACIÓN ACADÉMICA Y PROFESIONAL A LA HISTORIA MODERNA DE PORTUGAL Y ESPAÑA}

Irene $\mathbf{M}^{\mathbf{a}}$ Vicente Martín: Lo primero que quería preguntarle es por su interés por la Historia. ¿De dónde surge su vocación por esta disciplina?, ¿qué le llevó a dedicarse profesionalmente a ella?

Pedro Cardim: Siempre he sentido un gran interés por ubicarme en el tiempo y en el espacio. Recuerdo haber tenido siempre la inquietud de entender cómo habíamos llegado a un determinado lugar geográfico y cultural, y de qué manera y con qué características. Y siempre en relación con los otros. Este interés por entender cómo habíamos llegado y por qué estábamos en un determinado lugar, siempre vinculándolo a quiénes éramos y quiénes eran los otros, es lo que me interesó siempre. La doble dimensión de esta idea, para mí, era clara. Por una parte, me interesaba la localización en el tiempo y en el espacio pero, por otra, comprendía que esta localización no podía hacerse sin tener en cuenta la dimensión relacional de quiénes somos y quiénes son los demás.

Recuerdo sentir estas inquietudes desde fechas muy tempranas. Al principio de forma muy pueril y naif como puede suponerse, pero después, y más concretamente desde el momento en que decidí dedicarme profesionalmente a la Historia, de una forma más informada y científica. Responder a preguntas tales como ¿por qué somos lo que somos? o ¿por qué estamos aquí, en este momento concreto, y con estas características?, fue lo que me atrajo. Dar una respuesta a cada una de esas cuestiones era una tarea difícil, es también hoy una tarea difícil. Demanda mucho trabajo de reflexión y de lecturas, de reformulación constante de las preguntas y de los planteamientos, y de no darse nunca por satisfecho con las respuestas. Resumiendo, podría decir que mi interés por la Historia, a nivel personal y profesional, se debió a una intención clara y vocacional de conjugar la dimensión geográfica y cultural de una sociedad con su propia dimensión relacional. Es decir, descubrir cómo nos posicionamos, individual y colectivamente frente nosotros mismos y frente a los que consideramos los otros.

IMVM: En la búsqueda de estas respuestas por ubicarse, por ubicarnos, y por descubrir por qué estamos aquí en este momento cultural y geográfico, ¿qué fue lo que despertó su interés por el 'periodo español' de la Historia de Portugal?

Pedro Cardim: Fue un proceso gradual. Al principio no tenía la intención de que este tema fuera uno de mis frentes, pero para esa decisión contribuyeron dos maestros que me ayudaron mucho en mi formación académica y en mi inicial labor profesional. Estos dos maestros fueron, de una parte, António Manuel Hespanha en Portugal y de otra, Fernando Bouza Álvarez en España, ambos historiadores muy reconocidos internacionalmente y con una enorme calidad humana. Durante mi etapa de formación, hace algo más de veinte años, pude beneficiarme de su magisterio, de sus enseñanzas y de su capacidad de formación de estudiantes de Historia. En esas fechas ambos estaban trabajando temas relacionados con el lugar de Portugal dentro de la Monarquía Hispánica, aunque cada uno desde distintos puntos de vista que enriquecieron enormemente mi aprendizaje. António Manuel Hespanha abordaba este tema desde el punto de vista de la Historia del Derecho (Hespanha, 1994), mientras que Fernando Bouza lo hacía desde la perspectiva de la Historia Cultural del poder político (Bouza, 2000). La capacidad didáctica de ambos me descubrió y me abrió las puertas a un mundo historiográfico que, recuerdo, me pareció fascinante. Los temas que planteaban, 
las preguntas que suscitaban, y la sofisticación teórica y metodológica que ambos manejaban causó una atracción muy fuerte en mí.

Todo esto ocurrió, además, a finales de los años 1980 y comienzos de los 1990. Este periodo fue un momento de apertura historiográfica entre España y Portugal, apertura potenciada, en buena medida, por la integración europea y el crecimiento imparable de las universidades públicas. Como no podía ser de otra manera, esta apertura académica se extendió también hacia la Historia de los antiguos imperios coloniales, algo que sin duda renovó la forma de entender la Monarquía Hispánica. Yo tuve el privilegio de poder beneficiarme de este momento académico a través de mis dos maestros, quienes no sólo me enseñaron cuestiones teóricas sino que también me pusieron en contacto con importantes historiadores españoles, franceses, ingleses, italianos y americanos ya consagrados de su generación. De ellos también aprendí mucho, lo que me permitió ampliar mis horizontes y vincularme a estas nuevas perspectivas.

Gracias a mi formación y, a medida que avanzaba el tiempo, a mi progresiva experiencia, poco a poco fui dándome cuenta de que existían posibilidades diferentes de estudiar las relaciones entre Portugal y España en la Edad Moderna. Más concretamente, percibí que la forma de entender el lugar que Portugal había tenido dentro de la Monarquía Hispánica debía renovarse. De hecho, me di cuenta de que este periodo había tenido un peso importantísimo en la formación histórica de Portugal que la historiografía de corte nacionalista siempre había negado. Esa visión nacionalista, basada en el enfrentamiento de bloques y en la animadversión entre España y Portugal a lo largo de los siglos, debía superarse. Y debía superarse a través de una nueva Historia Política, Social y Cultural que, si bien debía seguir atenta a los conflictos, no podía obviar las interacciones, las influencias positivas y los procesos de mutua constitución que España y Portugal venían compartiendo desde siempre. No cabe duda de que a estas nuevas propuestas contribuyó mucho la discusión que al mismo tiempo se estaba llevando adelante en España acerca de la pluralidad y complejidad que la constituía. Es decir, la vieja idea nacionalista que apoyaba una España unívoca e identificada con Castilla estaba cayendo por aquel entonces, e importantes historiadores comenzaban ya a llamar la atención acerca de la necesidad de incorporar dicha pluralidad a las interpretaciones históricas. Para todos ellos, además, Portugal también ocupaba un papel de relevancia y formaba parte de esta complejidad hispánica, lo que enriqueció, qué duda cabe, la propia historiografía portuguesa. Como todos sabemos, estas nuevas concepciones tuvieron un impacto espectacular a ambos lados de nuestras fronteras.

IMVM: Entiendo. Eso respecto a lo que pasaba hace unos años pero, actualmente, aquí en Portugal, ¿qué atención se le presta al periodo de los Austrias?, ¿se imparte en las universidades?, ¿tiene buena aceptación por parte de los estudiantes?

Pedro Cardim: A raíz de esas herencias historiográficas, sí que es cierto que en los últimos diez años ha habido un creciente interés por los temas españoles en el mundo académico portugués. Han aparecido nuevas asignaturas de Historia, Cultura y Literatura españolas en general, y sobre el periodo de los Austrias en Portugal en particular, como 'Historia del Imperio español'. Dadas las relaciones intelectuales y culturales existentes hoy en día entre los dos países, creo firmemente que esta tendencia universitaria no sólo se mantendrá, sino que se verá reforzada.

Hoy el tema España se aborda, en las universidades de Portugal, desde una perspectiva muy normalizada. Es un tema que ya no despierta ningún temor, ningún rencor, ni 
tampoco se tiene ya la impresión de estar estudiando al enemigo. Al contrario, hoy en día se reconoce abiertamente la existencia de un componente hispánico en la formación histórica de Portugal en todos los ámbitos. Es decir, se reconoce la existencia de influencias que a nivel cultural, político, social, económico y literario vinieron de España e influyeron a Portugal. Y lo mismo ocurrió en el sentido inverso: Portugal impactó enormemente en la Historia de España. De hecho, yo imparto varias asignaturas de Historia de España en la facultad y mis estudiantes cada vez la consideran más útil para entender el pasado portugués. Ninguno manifiesta ya la idea caduca de oposición ni conflictividad entre ambos países, idea tan común en el pasado, sino que más bien todos buscan las interacciones, buscan los rasgos semejantes y diferentes presentes a ambos lados de la frontera, en los distintos contextos de la realidad peninsular y a todos los niveles.

De todas maneras, considero que a este cambio también han contribuido los ámbitos universitarios españoles. Allí también se presta una mayor atención a la realidad portuguesa en comparación a lo que se venía haciendo tiempo atrás. Ya no hay prejuicios nacionalistas como podía ocurrir hace años. Ya no hay miedos. Lo que hay son unas condiciones estupendas a todos los niveles para cultivar ese mutuo interés por comprender un pasado común.

IMVM: Supongo que esta ampliación de perspectivas no se habrá dado solo en España y Portugal, ¿no?

Pedro Cardim: No, para nada. Ha sido algo generalizado que ha tenido lugar en casi todos los países. En todo el mundo hoy se habla mucho de Historia Transnacional, de Historia Comparada, de miradas conectadas o de Entangled Histories. El objetivo de todos estos enfoques no es otro que poner en contacto distintos contextos, ya no solo de Europa Occidental, sino del mundo entero. Y conociendo como conozco específicamente la realidad portuguesa, creo firmemente que ese es el camino para una comprensión más adecuada del pasado.

Muchos creen que este tipo de enfoques proponen eliminar el marco nacional como referente para el análisis historiográfico, pero no, no se trata de eso. De lo que se trata es de añadir al marco nacional otras dimensiones, otras escalas, otros cuadros de análisis. En realidad lo que hay que hacer es adaptar dichas dimensiones y dichas escalas al tema concreto que se esté analizando. Dependiendo de los temas, el marco nacional, más que elucidar o ser explicativo, en realidad dificulta las interpretaciones de los procesos. Y máxime si esos procesos son complejos o se basan en dinámicas relacionales de interacción y de conexión. En este sentido, los procesos de 'mutua constitución', e insisto en esta expresión, tan comunes y presentes en la Época Moderna, no pueden entenderse si no es de forma conectada. Las interacciones, las interinfluencias, la circulación de personas, de las formas culturales o de los modelos políticos deben superar, obligatoriamente, esos marcos, pero no tienen por qué olvidarlos por completo.

Volviendo al caso concreto de Portugal y España, sí que es cierto que estos enfoques están más presentes y son más fuertes en su historiografía. El motivo puede ser que en los últimos quince años historiadores portugueses y españoles han puesto en marcha proyectos conjuntos de investigación con equipos multidisciplinares y multinacionales. Es muy fácil encontrar proyectos de historiadores de Évora con investigadores de Cantabria, de Santiago con Faro, de Lisboa con Barcelona o de Bilbao con Oporto, entre otros. El capital de experiencia y de conocimiento que ha surgido de ahí, así como 
la red de vínculos entre los dos países y la fluidez de trabajo conjunto, no ha hecho más sino reforzar unas conexiones que, propuestas a nivel teórico o académico, quedan demostradas con estas iniciativas. Otro motivo, no obstante, ha podido ser también el mercado de trabajo. Gracias a becas portuguesas muchos centros de investigación han acogido a un número significativo de investigadores españoles, sobre todo recién doctorados. De manera paralela también historiadores portugueses han podido disfrutar de estancias en España trabajando con colegas españoles. Como puede suponerse, todo esto ha contribuido a acercar historiografías, metodologías y a crear comunicación entre las áreas, favoreciendo fuertemente el diálogo y la interlocución, tan necesario para entender los dos países en su totalidad.

\section{EL PAPEL DE BRASIL EN LA HISTORIA DEL MUNDO MODERNO (SIGLOS XVI-XVIII)}

IMVM: En este ámbito historiográfico acerca de las interacciones de Portugal y España en la Época Moderna, ¿cómo se ha integrado la Historia de Hispanoamérica?, ¿y la Historia de Brasil?

Pedro Cardim: La integración de toda América Latina pero, específicamente la integración de Brasil en esta dinámica historiográfica, es muy interesante. Sí que es cierto que cada país ha tenido ritmos específicos, pero el proceso, visto en su conjunto, es revelador.

Desde hace veinticinco años viajo a España con relativa frecuencia para trabajar con colegas españoles. Sí que es cierto que al principio muy poca gente allí se interesaba por el pasado de Brasil, algo que contrastaba mucho con la atención que desde siempre se le ha prestado a Hispanoamérica. Hoy se aprecian importantes cambios, sobre todo a partir de la creación, en la Universidad de Salamanca, de áreas de trabajo dedicadas al estudio de Brasil en general, y al periodo en el que Portugal formó parte de la Monarquía de los Austrias en particular. Estas áreas de trabajo han contribuido mucho a fomentar el estudio de las relaciones entre la América española y Brasil, pero también entre Brasil y Portugal. La separación que tradicionalmente se hizo en las aulas entre la Historia de América y la Historia Moderna tuvo consecuencias muy graves. Por fortuna, en tiempos recientes, esta separación ha podido superarse. Afirmo con certeza que esto también puede deberse a que estamos en un momento de mayor interés e integración de la Historia colonial lo que obliga, sin lugar a dudas, a contar con los espacios americanos para el conocimiento completo de la Historia de Portugal y España.

¿Dónde está Brasil en esta nueva perspectiva, en esta mirada nueva? De manera concreta, Brasil poco a poco está ganando espacio en el abanico de cuestiones que los historiadores americanistas españoles se plantean. La percepción que se tiene de Brasil como un espacio conectado con la América española, concretamente con el Virreinato de Perú, ha suscitado los intereses de buena parte de la academia. En este sentido, los trabajos de José Manuel Santos han jugado un papel fundamental en el desarrollo de estas nociones de conexión en el periodo de los Austrias, pero también quiero destacar la importancia de los estudios sobre la trata de esclavos hechos en la Universidad de Sevilla (Vila Vilar, 2014). Y esto no se queda aquí. Yendo más lejos, me atrevería a decir que el interés por el pasado de Brasil se está convirtiendo en un fenómeno general, como puede deducirse también de las importantes contribuciones que han hecho los historiadores americanos. Por ejemplo, en Argentina son comunes 
los estudios sobre las relaciones entre el río de la Plata y Brasil, y en México abundan los trabajos sobre los conversos portugueses en el mundo novohispano y caribeño, por citar algunos de ellos.

No obstante, si bien el panorama es alentador y los avances significativos, creo que queda mucho trabajo por hacer al respecto. Integrar Brasil en la Historia Moderna de Portugal y España es un trabajo complejo. En primer lugar, supone el manejo de tradiciones historiográficas enormes. Trabajar sobre Brasil implica, por un lado, trabajar con la Historia de España y Portugal; por otro, con la historiografía brasileña en toda su diversidad, ya que Brasil es un país enorme con tradiciones historiográficas múltiples dentro de sí mismo; y finalmente, dominar las muchas historiografías de Hispanoamérica y su pasado colonial. A esto debe sumársele, a mayores, el estudio de los pueblos amerindios, es decir, de las sociedades indígenas de entonces y de ahora. Es una gran tarea de conectividad de las distintas tradiciones historiográficas que, si bien todas ellas son muy ricas, también son verdaderamente complejas, con una gran cantidad de líneas de trabajo, de enfoques y de metodologías.

En segundo lugar, por su parte, Brasil ya no puede entenderse sin su dimensión atlántica, es decir, sin sus conexiones con África, motivadas principalmente por el tráfico de esclavos. Tampoco pueden entenderse Portugal y España sin sus relaciones africanas. De hecho, yo creo que a mayores de la conexión entre las historiografías americanas e ibéricas, el gran desafío de los próximos años va a ser precisamente ese: la inclusión de África y los actores africanos y afrodescendientes no sólo en el mundo americano, sino en los ámbitos historiográficos propiamente europeos. Al igual que ocurre con las comunidades indígenas de Brasil, estas inclusiones obligan a trabajar con otro tipo de fuentes, planteamientos e incluso disciplinas diferentes a la Historia, como la Etnohistoria o la Antropología, no tan comunes en la investigación histórica.

Por tanto, la inclusión de Brasil en este ámbito de estudio, aunque es algo necesario y está ya puesto en marcha, es complicado y va a llevar su tiempo. Conectar a la Historia de América, Portugal y España, la Historia de Brasil y, en consecuencia, la Historia Atlántica y de África va a ser el gran desafío. Fascinante y revelador, sí; pero cargado de dificultades.

IMVM: Como se puede ver en muchos de sus artículos, reagrupados ahora en un nuevo volumen recién publicado, su propia trayectoria ha seguido el camino recién descrito (Cardim, 2017). ¿De dónde viene, en su caso personal, este viraje?

Pedro Cardim: Yo soy un historiador formado en Historia de Europa. Durante años me centré en el estudio del contexto europeo en consonancia con mi formación inicial pero, en los últimos diez años, he empezado a interesarme por la realidad americana y atlántica por distintos motivos. Por una parte, este interés ha venido a través de mi puesto de vicedirector en el Centro de Humanidades-CHAM de la Universidade Nova (Lisboa). Gracias a este puesto he tenido la fortuna de trabajar con profesores y colegas brasileños durante sus estancias en Lisboa y de conocer sus tesis y sus enfoques plasmados en sus investigaciones. Eso despertó un importante interés en mí hacia la realidad americana.

Por otra parte, y de forma simultánea, mi propio trabajo sobre la realidad ibérica portuguesa y española muy pronto me dirigió hacia América. Si se piensa un poco, entender a fondo la realidad de Portugal y España durante la Edad Moderna debe pasar, obligatoriamente, por el pasado colonial e imperial que tuvieron estos dos países, y dicho 
pasado está en la Historia de América. En mi caso específico, al intentar comprender de qué forma se percibía la realidad imperial en Portugal en el siglo XVI, hube de incluir en mis preguntas a Brasil. Puedo afirmar que mi propósito no ha sido hacer Historia de América, sino que me acerqué a ella por esta necesidad de comprender Portugal y su dominación colonial en América en toda su complejidad.

Así, mientras trabajaba sobre la realidad peninsular portuguesa y a partir de lo aprendido con A. Manuel Hespanha, con F. Bouza, con J. Elliott, con B. Clavero, P. Fernández Albadalejo, S. Schwartz, J.-F. Schaub, X. Gil Pujol y con otros historiadores que se centraban en la configuración territorial de las monarquías ibéricas, entendí que muchos conceptos o categorías que se aplican en la actualidad tuvieron un significado muy distinto en los siglos XVI y XVII. Palabras como 'imperio', 'colonia', 'colonial', 'conquista' o 'ultramarino' no significan ahora lo mismo que entonces, y por eso quería estudiarlas en su contexto histórico. El entendimiento de las monarquías modernas ibéricas debía pasar, indudablemente, por este entendimiento semántico en su totalidad. Fue a partir de ese interés por los conceptos, las palabras y las categorías clasificatorias como fui aproximándome al mundo americano y ultramarino en general. Pero sin imponer sus significados actuales, repito, sino intentando siempre respetar el significado que españoles y portugueses les atribuyeron en los siglos XVI y XVII. Al final casi ha sido aplicar la misma receta, las mismas preguntas que había planteado para el Portugal peninsular y su integración territorial en la Monarquía Hispánica, al contexto americano colonial y, concretamente, a Brasil.

IMVM: Este cambio de perspectiva no habrá sido tarea fácil...

Pedro Cardim: Claro, en esa tarea se corren varios riesgos. Uno de ellos, y quizá el más habitual, es el de caer en interpretaciones eurocentristas. En mi caso, mi trabajo con colegas brasileños y con colegas de la Universidad Pablo de Olavide me volvió mucho más sensible a los peligros de adoptar posturas anacrónicas o eurocéntricas en mi concepción del mundo ultramarino portugués. También me ayudó mi relación con historiadores españoles y el conocimiento de sus estudios sobre Hispanoamérica. Por ejemplo, la colaboración en el programa de posgrado sobre Historia de América colonial de la Universidad Pablo de Olavide, como ya he dicho, o el planteamiento que José Manuel Santos desarrollaba sobre Brasil, también mencionado, me ayudaron enormemente. ¿Por qué separar la Historia de Brasil del resto de la Historia de la América colonial de los s. XVI, XVII y XVIII? La perspectiva historiográfica eurocentrista y nacionalista, que también existe en América, daba paso a una visión mucho más integradora en la que Brasil no podía y no debía entenderse sin el resto del continente.

Curiosamente, y de forma paralela, me di cuenta de que a veces era más fácil para historiadores provenientes de otros países desarrollar miradas integradas y tender puentes historiográficos entre Europa y América. Por ejemplo, al conocer los trabajos del historiador norteamericano Lewis U. Hanke publicados en los años cincuenta y sesenta sobre las interacciones entre el Brasil de los Austrias y el Virreinato de Perú, y los de su discípulo, Stuart B. Schwartz (1973) que siguió un camino parecido, me di cuenta de que las preguntas estaban ya planteadas en sus investigaciones. Es decir, yo no estaba inventando gran cosa. Lo que estaba haciendo era retomar preguntas ya formuladas para otras áreas y desde otras perspectivas, y añadirle escalas de análisis nuevas y problemáticas más actuales. Esto es lo que siempre sentí y lo que siento también ahora: que estoy retomando aquellas preguntas pero aplicándolas a nuevos contextos. 
IMVM: ¿Es este enfoque extra europeo y globalizador el objetivo de los trabajos que aparecieron en Polycentric Monarchies (Cardim, Herzog, Ibáñez \& Sabatini, 2012)?

Pedro Cardim: En Polycentric Monarchies se recoge el trabajo desarrollado durante algunos años con un grupo de historiadores interesados en una Historia conectada de las dos monarquías ibéricas. Me refiero a grupos de investigación integrados en 'Red Columnaria', inspirados en lo que fueron los desarrollos historiográficos de los años 1980 y 1990 . En esas décadas, las monarquías de la época moderna fueron sometidas a estudio, apareciendo la nueva Historia política, la 'Monarquía Compuesta' o las críticas a la categoría de Estado. Todas estas nuevas maneras de entender las formaciones políticas de la Edad Moderna buscaban entender el poder, la dominación y su ejercicio en los territorios que componían la Monarquía Hispánica de una forma mucho más plural y compleja. Al final, lo que hemos hecho en Polycentric Monarchies en términos teóricos no es tan novedoso como algunos han pensado. Como ya he dicho, hemos retomado propuestas de Bartolomé Clavero, de António Manuel Hespanha, de la historiografía del derecho italiana representada por Paulo Grossi o Pietro Costa, pero aplicándolas al mundo de la América colonial.

El objetivo fundamental era comprender cómo la dominación de la Monarquía Hispánica se concretó en América y se mantuvo durante tanto tiempo. Lo que hemos intentado ha sido observar ese mundo a la luz de los paradigmas historiográficos de la Historia Política y, al mismo tiempo, sacar partido de aquellas otras corrientes de corte social que dan visibilidad a los agentes locales y a los pueblos sometidos como actores del proceso histórico, colectivos que hasta ese momento no habían tenido la atención que merecían. Es decir, la genealogía historiográfica de este conjunto de cuestiones, como ya he dicho, la ubico en el mundo de la Historia del Derecho y en la renovación de la Historia de las monarquías ibéricas que ocurrió en 1980 y 1990, a lo que se unen estudios más actuales como la idea de agency de los actores locales. Pero como digo, la idea del libro es sobre todo esa: aplicar las cuestiones ya planteadas por la Historia y otras disciplinas, al caso de la América colonial durante la Edad Moderna, algo que no se había realizado en profundidad.

No obstante, el libro está un poco incompleto. Nos han faltado capítulos sobre el contexto africano y el contexto asiático. Y nos faltan, también, capítulos sobre un abanico más amplio de actores. Asimismo, la ausencia de la violencia, la dominación o la destrucción en el conjunto del libro es evidente. Esto ha hecho que algunos historiadores, sobre todo especialistas en comunidades indígenas, africanas y de afrodescendientes hayan quedado un poco contrariados. Les ha parecido que el libro intentaba presentar una imagen rosa de la dominación ibérica en América, en Asia y en África. No era esa la intención. Todo lo que está presente en el libro implica destrucción, conquista y violencia. Lo que intentamos mostrar es que todos estos procesos deben ser vistos y analizados en un contexto específico, en el que el poder y la autoridad fueron ejercidos de una forma mucho más compleja y plural de como siempre se ha pensado. El abanico de personajes activos y sujetos de la historia es mucho más amplio y variado de lo que siempre se ha supuesto. La tradicional imagen dicotómica de dominadores y dominados es simplista y ya no funciona, pero tampoco puede obviarse ni ocultarse. 


\section{EXPLICAR EL PASADO PARA ENTENDER EL PRESENTE: PORTUGAL, ESPAÑA Y BRASIL, AYER Y HOY}

IMVM: En esta intención de aplicar al pasado conceptos y categorías actuales, como puede ser centro y periferia, conquistadores y conquistados, colonia y poder... ¿qué opinión le merece la idea del lberismo, es decir, de apostar por una unión de España y Portugal? ¿Cree que tiene bases políticas o es una idea romántica?

Pedro Cardim: No creo que el Iberismo sea el camino. Yo soy un europeísta convencido y me parece que es mucho más productivo pensar en estas ideas de interacción y unión a escala europea. Yo creo en una Europa cosmopolita, abierta y multicultural, y las relaciones entre Portugal y España deben ubicarse en ese ámbito. Y deben de ser sobre todo, relaciones fluidas, intensas, ricas y productivas para todos los partícipes de esa relación, ya sean personas del mundo académico o de la sociedad en general.

Sin duda alguna estas relaciones deben dar continuidad a las que existieron en el mundo ibérico a finales del siglo XVI, XVII, XVIII e incluso XIX que, truncadas por el auge de los nacionalismos, siguieron funcionando después y lo siguen haciendo hoy. Pero todas esas relaciones deben basarse, como ya he dicho, en la pluralidad, en la aceptación de las diferencias y en coexistencia de las diversidades. En este sentido hablaría de Iberismo como un conocimiento profundo de la diversidad interna de las sociedades que habitan el espacio peninsular, pero no como un Iberismo político.

Sin embargo, en Portugal es necesario conocer mejor la riqueza y variedad cultural española y no reducirla a Castilla y Madrid o al bloque castellano frente al bloque catalán. Los portugueses tienen mucho que ganar con esa comprensión global de la España plural. Y creo que se está logrando en muchos ámbitos. Aparte, creo que este planteamiento de lberismo cultural y relacional es totalmente válido para todo el mundo ibérico, incluyendo América, no solo para los dos países peninsulares, siempre y cuando se haga a partir de unas relaciones fluidas, intensas, productivas y ricas, pero siempre con el compromiso del respeto a la pluralidad por delante.

IMVM: A raíz de esa diversidad, y recordando la divulgación que la revista Sàpiens hizo de una entrevista suya con una intencionalidad clara (Cardim, 2014, 24 de febrero), ¿qué opinión le merece la actual situación en Cataluña a la luz de la historia y del contexto actual ibérico y europeo?

Pedro Cardim: En realidad, me cuesta mucho entender cualquier tipo de nacionalismo, porque yo no soy nacionalista. Respeto algunos sentimientos nacionales y, en el contexto específico catalán, respeto también algunas de las formas que ese sentimiento tiene de expresarse. No obstante, me parece que estamos ante una situación muy compleja que requiere medidas políticas prudentes. Todos los actores de ese proceso deben tener la empatía y la sensibilidad para llegar a un acuerdo que, pasando por la política, por concesiones de parte a parte, o quizá creando o reinventando un contrato o un acuerdo de convivencia y de aceptación de las diferencias, beneficie en última instancia a la sociedad. El problema, yo creo, es eminentemente político, como en otros nacionalismos que se han planteado en España y por eso la solución debe pasar por la política. Desde luego, no creo que imponer una solución de forma unilateral sea la mejor propuesta. Pero es cierto que hay que llegar a un compromiso político por las partes afectadas. Es evidente que no hay solamente dos partes, dos bloques, sino una mayor diversidad de sensibilidades y de planteamientos que tanto a nivel político como social 
están presentes y se ven afectados.

IMVM: Para finalizar, volvamos la atención de nuevo a Brasil. Dado el pasado común de España y Portugal tanto en Europa como en América, ¿qué papel deberían desempeñar estos dos países para acercar Brasil, el gran desconocido, a los ámbitos sociales y académicos europeos?

Pedro Cardim: Creo que en estos momentos se dan todas las condiciones para que Portugal y España adquieran este papel de canal entre Iberoamérica y Europa, siempre y cuando no asuman una actitud paternalista, neocolonialista ni eurocéntrica como a veces ha sucedido. España y Portugal han compartido con Iberoamérica un pasado y una historia. Desde luego ha sido una historia dura, con conflictos, tensiones y explotación, pero también con numerosas experiencias compartidas que han proporcionado complicidades y enriquecido las culturas.

España y Portugal deben hablar de esa historia frontalmente, sin miedo a tocar los temas sensibles, y sin temor a reconocer la responsabilidad que tuvieron españoles y portugueses en muchos de los problemas que afectan hoy en día al mundo latinoamericano. Y sobre ese diálogo, deben construir una relación justa y equilibrada, sensible a la diversidad cultural, lingüística y étnica que implique un mejor conocimiento de América en los círculos de Europa. Es decir, portugueses y españoles, partiendo de la fascinante diversidad y dinamismo de Brasil y de Hispanoamérica, tienen en su mano la posibilidad de crear una relación que sea productiva para todas las partes.

Pero también tienen en su mano la obligación de incorporar África a través de este diálogo. Es decir, deben favorecer conexiones en las que no sólo Portugal tenga la responsabilidad de incorporar los países lusófonos de África, sino que también España colabore dadas sus relaciones con este continente. España y Portugal tienen la oportunidad de construir una auténtica comunidad de pueblos de habla española y portuguesa, tanto en América como en África, y darla a conocer en Europa. Por verdadera comunidad entiendo una comunidad que sea un ejemplo de respeto por la multiplicidad cultural, étnica y lingüística, respeto por la diferencia, por los saberes de los distintos actores de las sociedades europeas, latinoamericanas y africanas que están en contacto y en comunicación, ya no solo en Madrid, Lisboa, Rio de Janeiro, Lima o Buenos Aires, sino también en cualquier país africano en los que se detecten influencias. Pero huyendo, insisto, de cualquier desviación eurocentrista, paternalista o neocolonialista.

IMVM: Es decir, buscando y respetando no solo la diversidad de estos países, sino también la diversidad de las sociedades en sí mismas, ¿no?

Pedro Cardim: Claro, que la interacción entre España, Portugal, América y Europa sea, al final, el espejo de la diversidad de dichas sociedades, entendiendo siempre esa diversidad como una riqueza intrínseca de las mismas.

IMVM: Profesor Cardim, muchas gracias por su colaboración, por su tiempo y por sus reflexiones. Creo que muchos de los temas tratados han sido verdaderamente interesantes.

Pedro Cardim: Ha sido un placer. Gracias a usted. 


\section{REFERENCIAS BIBLIOGRÁFICAS}

Bouza Álvarez, F. (2000). Portugal no tempo dos Filipes: política, cultura, representações (1580-1668). Lisboa: Cosmos.

Cardim, P. \& Miranda, S. M. (2015). A incorporação de territórios e o estatuto político do espaço ultramarino. In J. Fragoso \& M. F. Gouvêa (Org.). O Brasil Colonial. A Dinâmica dos Pactos e Conflitos entre os Impérios (pp. 51-106). Rio de Janeiro: Civilização.

Cardim, P. \& Zúñiga, J. P. (2013). Les représentants de municipalités extra-européennes dans les Cortes de Portugal. In J. P. Zúñiga (Org.). Negociar la obediencia. Autoridad y consentimiento en el mundo ibérico en la Edad Moderna (pp. 47-62). Granada: Comares.

Cardim, P. (2004). O governo e a administração do Brasil sob os Habsburgo e os primeiros Bragança. Hispania: Revista española de historia, 216, 117-156.

Cardim, P. (2014). Portugal, Catalunha e Espanha ou o uso que o nacionalismo faz da história. Publico. Recuperado de [https://www.publico.pt/2014/02/25/culturaipsilon/opiniao/portugal-catalunha-e-espanhaou-o-uso-que-o-nacionalismo-faz-da-historia-1626114]. Consultado [06-05-2018]

Cardim, P. (2014). Portugal unido y separado. Felipe II, la unión de territorios y el debate sobre la condición política del Reino de Portugal. Valladolid: Ediciones Universidad de Valladolid.

Cardim, P. (2016). Political status and Identity: Debating the Status of American Territories Across the Sixteenth and Seventeenth Century Iberian World. Rechtsgeschichte-Legal History, 24, 101-116.

Cardim, P. (2017). Portugal y la Monarquía Hispánica (ca. 1550-ca.1715). Madrid: Marcial Pons Historia

Cardim, P., Herzog, T., Ruiz Ibáñez, J. J. \& Sabatini, G. (2012). Polycentric Monarchies How did Early Modern Spain and Portugal Achieve and Maintain a Global Hegemony? Brighton: Sussex Academic Press.

Cardim, P.; Krause, T. (2016). A comunicação entre a Câmara de Salvador e os seus procuradores em Lisboa durante a segunda metade do século XVII. In E. S. Souza, G. Marques \& H. R. Silva (Org.). Salvador da Bahia: Retratos de uma cidade atlântica (pp. 47-98). Lisboa: CHAM.

Hanke, L. U. (1956). The imperial city of Potosí. An unwritten chapter in the history of Spanish America. Potosí: Nijhoff.

Hespanha, A. M. (1984). As Vésperas do Leviathán. Instituições e poder político em Portugal, séc. XVII. Lisboa: Almedina.

Megiani, A. P. T., Santos, J. M. \& Silva, K. V. (Org.). (2014). O Brasil na Monarquia Hispânica (1580-1668). São Paulo: Humanitas.

Schwartz, S. B. (1973). Sovereingty and society in colonial Brazil: the High Court of Bahia and its judges, 1609-1751. Los Angeles / Londres: University of California Press / Berkeley.

Vila Vilar, E. (2014). Hispanoamérica y el comercio de eslavos. Sevilla: Universidad de Sevilla. 